九州大学学術情報リポジトリ

Kyushu University Institutional Repository

\title{
Chen Zhen and the Obviousness of the Object
}

Vincent-Goubeau, Anne

University of Angers : Professor of Visual Arts and Theory of Arts

Bouillon, Pierre

Faculty of Humanities, U. C. 0. Angers

https://doi.org/10.5109/1806130

出版情報: Journal of Asian Humanities at Kyushu University. 2, pp.47-56, 2017-03. Kyushu University, School of Letters, Graduate School of Humanities, Faculty of Humanities バージョン:

権利関係 : 


\title{
Chen Zhen and the Obviousness of the Object
}

\author{
ANNE VINCENT-GOUBEAU \\ TRANSLATED BY PIERRE BOUILLON, \\ FACULTY OF HUMANITIES, U.C.O. ANGERS
}

1 Born in Shanghai in 1955, Chen Zhen grew up in a family of doctors speaking French and English, in the district of the former French concession in Shanghai, during the years of the Cultural Revolution. At that time, the only school of art in the city provided a traditional education where he learned painting, drawing, and sculpture. Curiously, this traditional pedagogy offered Chen his first contact with Western art. He became a painter and professor in Shanghai. At the age of twenty-five, he continued his studies at the art school with the Shanghai Theater Institute where he considered the question of the physical relation of art works with the spectator. In 1980, he discovered that he suffered from autoimmune hemolytic anemia, a rare and incurable disease. In 1986, when he was thirty-one, Chen arrived in Paris where he became a visiting pupil at the Beaux Arts, and abandoned painting to devote himself to installations. He studied at the Institute of Advanced Studies in Plastic Arts where he later taught from 1993 to 1995 . Chen exhibited at numerous international institutions including The New Museum of Contemporary Art (New York, 1994), the Center for Contemporary Art (Kitakyushu, Japan, 1997), and the Venice Biennial (1999). He died on December 13, 2000.

2 "I worked very hard, day and night. It might be a period in my entire life during which I worked the most and my thoughts were most concentrated. Few people would understand this. At that time, my family did not come to Paris yet. I was alone, living an extremely simple life. I did not need much at that time. I rented

he was forcibly immersed in a foreign culture whose specific background and particular features he strove to make his own. Drawing on such radical experience, based on openness and interchange, he produced a powerful, generous body of work consisting mainly of artistic installations. Tensions existing between direct opposites were repeatedly played upon in his artwork, whose power lay in the implementation of a simple visual arts language in sober unaffected installations. Along with the growth of interest in expatriate Chinese artists beginning in the 1990s, commitments by museums to exhibit international artists, and the tireless work of Chen's widow, Xu Min, Chen was a highly visible international art figure. His work derives from his

\footnotetext{
a small servant room about seven square meters in size on the outskirts of Paris, 'hiding in a small attic, oblivious of all four seasons.' I lived like that for four years! Sometimes, I did not make any phone calls to anybody for a whole month, and nobody had any correspondence with me. Do you know what kind of life that was? A life in which you really felt you were a heavenly steed soaring across the skies and doing whatever you truly wanted! I had the rarest type of quietness and deep thinking in life!" Quoted from Transexperiences: A Conversation between Chen Zhen and Zhu Xian, ADAC (Association Des Amis de Chen Zhen, https://www.chenzhen.org (consulted January 7, 2017).
} 


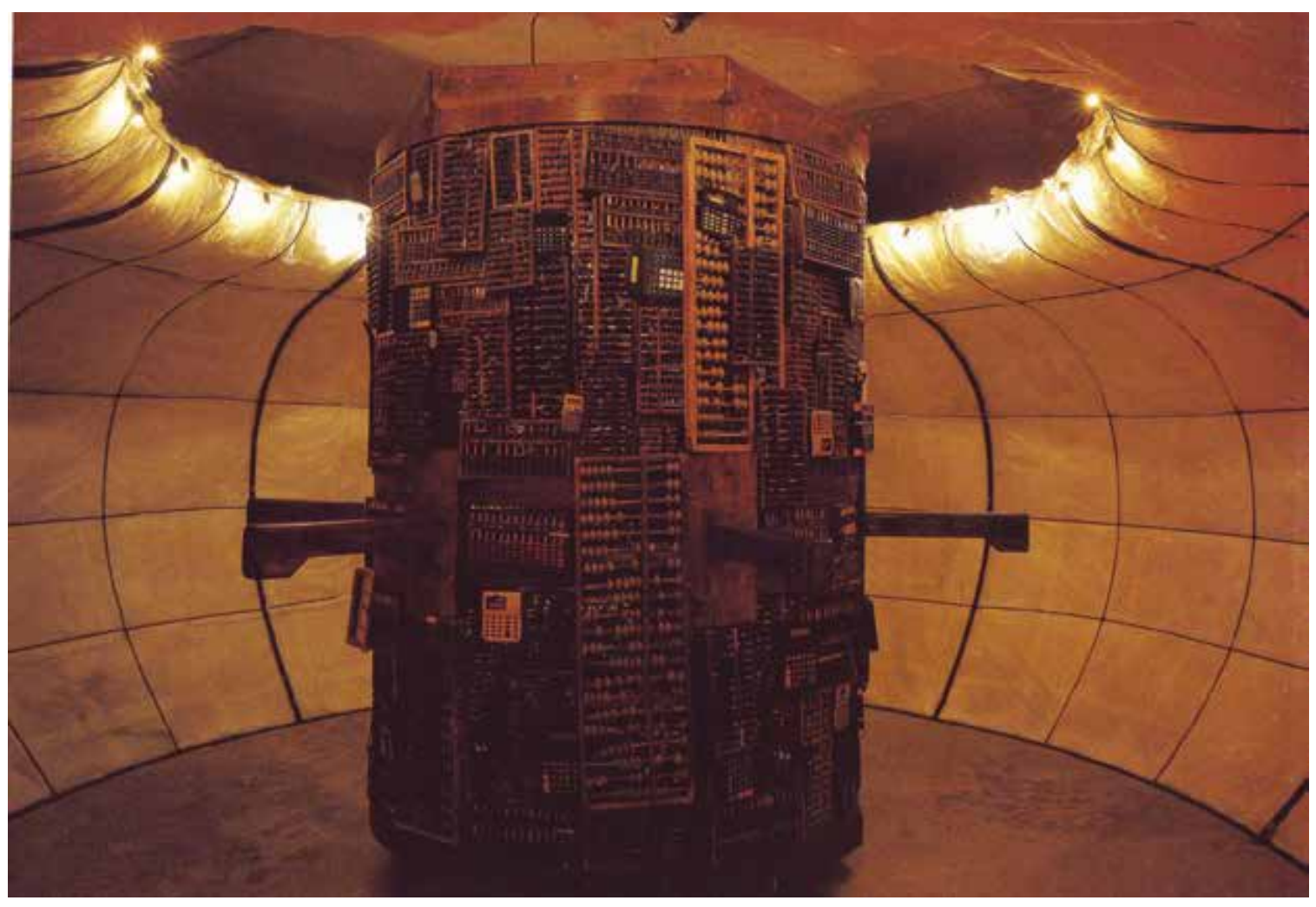

personal experience of migrating and working across different continents and cultures. The artist drew inspiration from his own life experience, travelling between Paris and his native city of Shanghai, responding to and engaging with contemporary social issues across different cultures.

This essay will emphasize the importance of the time Chen spent in Tibet in $1983^{3}$ to his development as an artist. There, the need he felt for interiority, ${ }^{4}$ closely

3 Responding to an order from the Communist Party, Chen made a forced trip to Tibet in 1983; it would be a turning point in his life. He discovered the importance of prayer and spirituality. The account of this three-month experience expresses his work based on what he calls "cultural shortcuts." The fascination that Tibet, and by extension Tibetan Buddhism, holds over the artistic and personal inspirations of mainland Chinese artists is an important and controversial trope that is not limited to Chen Zhen. Other examples include Ai Weiwei (b. 1957 in Beijing), Huang Yong Ping (b. 1954 in Xiamen) and Zhang Huan (b. 1965 in An Yang).

4 The interiority, the quality of what is interior, refers to what is presented as an experience of subjectivity. In this context, the interiority is spiritual, of the domain of personal intimacy, and sensitive to the requirements of transcendence.
Figure 1. Chen Zhen. Prayer Wheel-"Money Makes the Mare Go" (Chinese Slang). 1997. Whole: H. $260 \mathrm{~cm}, 1.700 \mathrm{~cm}$, w. $280 \mathrm{~cm}$. Wheel: D. $240 \mathrm{~cm}$, h. $250 \mathrm{~cm}$. Chinese abacus, calculators, cash registers, metal, wood, sound system. Source: David Rosenberg and Xu Min, Chen Zhen. Invocation of Washing Fire, 235.

linked with Buddhism, grew alongside his desire for "a body of work that touches profoundly on human preoccupations whilst keeping a very personal visual vocabulary and way of thinking." Everyday objects were at the very core of his site-specific installations. Chen took such objects out of their original environment and dematerialized and transformed them, thus imparting a new metaphorical role to them.

This paper will examine Chen Zhen's wish to go beyond the first apparent interpretation of an object by fitting it into a specific environment that more often than not will question the viewers' convictions. One

5 Jérôme Sans, Chen Zhen: The Discussions (Dijon: Les presses du réel, Domaine Ecrits d'artistes, 2003), 195. 
example of this is Prayer Wheel- "Money Makes the Mare Go" (Chinese Slang) (figure 1), an artwork created in New York in 1997. This installation is executed with trivial objects within a device belonging to the religious domain. It draws directly on his three-month stay in Tibet shortly before he left for Europe. In 1986, after Deng Xiaoping's reforms, Chen immigrated to Paris and studied at the Ecole des Beaux-arts and the Institut des Hautes Etudes en Arts Plastiques, where he would eventually teach from 1993 to 1995 . He would later also teach at the Ecole des Beaux-arts in Nancy. He did not go to Tibet on his own accord, but his time there decisively influenced his art while also shaping his personal life and philosophical outlook on humanity. Chen's artwork cannot be separated from his life-the way he looked at the world and considered creation. From a spiritual point of view, Tibet opened his eyes. He was impressed with the simplicity that characterized people's everyday lives. It seemed to him that they led lives of endless rituals. He said:

Tibetans face extremely harsh natural conditions and their physical life is closely tied to their religious and spiritual beliefs. This results in outstanding stamina and quietness, a way of life impervious to the attraction of material things. ${ }^{6}$

He was seriously ill at the time and recalled spending three months "cleansing" and "purifying" himself. Every day he would perform a most important task: spinning a prayer wheel. This is how he described the experience:

It filled me with very strange feelings, and extraordinary mental illuminations. I managed to get into a Tibetan temple usually closed to the public, where I heard the monks reciting prayers. Facing my body with an 'immaterial environment' was a unique experience. That confrontation was beneficial both physically and spiritually. That experience still nurtures me today and gives me both inspiration and energy for my work. ${ }^{7}$

Chen's thinking is closely linked with Buddhist spiri-

6 Eleanor Heartney, "Chen Zhen, 'entre' les cultures," Artpress 260 (2000), 25.

7 David Rosenberg and Xu Min, Chen Zhen. Invocation of Washing Fire (Prato-Sienne: Editions Gli ori, 2003), 40. tuality, which, for him, should never be turned into a doctrine. He read extensively in Tibetan Buddhist texts, including the Bardo Thodol (Book of the Tibetan Dead $)^{8}$ and The Hundred Thousand Songs of Milarepa (1040-1123), a renowned master of Tibetan Buddhism. The time he spent mixing with Tibetans changed his perspective and made him pay closer attention to everyday realities. At the core of his thinking was the link between man, nature, and consumerism. The human being and Chen's environment were at the center of his preoccupations and his artistic approach. For him, everything was a matter of looking within a world that he discovered and experienced. Entering a Tibetan temple, he could hear a monk launching into a prayer but eventually understood that the voice in reality came from a tape deck, which surprised him. He was then touched by the sight of a clay statue of Buddha that sat on top of the appliance and that bathed in a beam of light similar to a spiritual halo. He remarked, however:

The monks had the same serenity and piety as if they were following the real voice of their spiritual father! Whereas with a western eye one could see a living bi-cultural installation, an oriental Lavier! ${ }^{9}$

The reference to Bertrand Lavier is an interesting one, since this French contemporary visual artist challenges and freely associates categories, codes, genres, and materials so as to disconcert the viewer. He brings together objects belonging to different worlds and times as in the installation Husquarna/Art Déco (2012, figure 2), in which a high-tech leafblower hovers over an art

8 This book was discovered in the fifteenth century and appeared in the West in 1927. The source of this text comes from Padmasambhava ( $f$ l. eighth century), an Indian sage who introduced Buddhism to Tibet. Bardo means "intermediate state" more precisely the states of consciousness after death, which are three in number: the state of the moment of death, the state of the supreme reality, and the state of becoming, which appears in the phase of preparation for rebirth. This book had a certain influence on the true meaning of life, how to accept death, and how to help the dying.

9 Bertrand Lavier (born in 1949 in Châtillon-sur-Seine, France) lives and works in Paris. In the 1980s and 1990s, Bertrand Lavier was known for his readymades, created by covering everyday industrial objects such as refrigerators, tables, pianos, and furniture with an impasto layer of paint. He appropriates ubiquitous objects and images in order to reposition them as elements in a strategic critique of consumerism, deeply entrenched visual habits, and art institutions. 


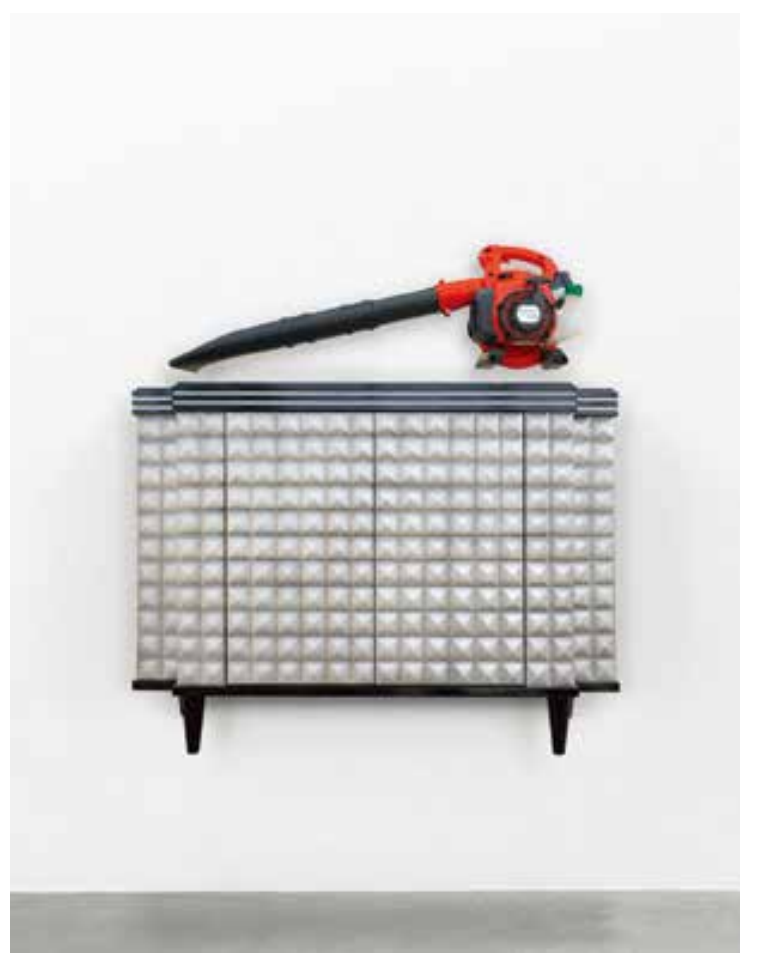

Figure 2. Bertrand Lavier. Husqvarna /Art Déco. 2012. H. $132 \mathrm{~cm}$, I. $124 \mathrm{~cm}$, w. $45 \mathrm{~cm}$. Leaf blower, piece of Art Déco furniture. Photograph used with permission of Radio France, www.franceinter.fr/info/lejour-ou-husqvarna-embrassa-art-deco.

deco piece of furniture from the 1930s. The impossible encounter between these two objects on a wall highlights the temporal, functional, and aesthetic disparity between them, offering an unusual and unexpected dialogue. Chen plays with objects in a similar way, juxtaposing cultures: Western and Asian, traditional and contemporary.

Chen's artwork is based on the self-evidence of mundane objects. He sees objects both as keepers of ancient memories and as witnesses of a society undergoing a process of radical transformation. The potential hidden in each object is what he is truly interested in. The object in itself and its relationship to human life are both of the essence, as is the way that it can shift from one cultural context to another. Prayer Wheel- "Money Makes the Mare Go" (Chinese Slang) invites observers to enter a cozy, confined space, an igloo made of crumpled tissue paper suffused with a subdued reddish glow. When visitors encounter a huge cylinder whose sur- face is coated with a hundred or so Chinese shields, the mystery remains unsolved, and they are at once puzzled and curious. The handles attached to the wheel, moreover, incite them to set it in motion. As a consequence, visitors find themselves involved by setting off the sound of cash registers and calculating machines stuck between the shields. They thus become responsible for triggering an unstoppable materialistic spiral.

The viewer cannot help feeling unsettled because a prayer wheel (Tib. mani korlo) is normally a cylinder filled with mantras. It is traditionally believed in Tibet that spinning such a wheel is the spiritual equivalent of reciting the mantra. The prayer is thought to disperse into the air as if it had really been spoken. Spinning the cylinder sets in motion the energy of the prayers it contains. Such cultural hybridization between two very different worlds is astounding since a Buddhist religious object is, here, associated with iconic artifacts of a consumer society. Paradoxically, the artist confronts the occidental viewer with the cult of capitalism by asking him to set in motion a huge object.

The sounds of cash registers combine with the sounds of a collection of ancient and modern calculating machines. The use of the Chinese abacus (Ch. suan pan 算盘) is relatively unknown to people in the West, even though it was used ubiquitously across Asia. It has existed in China for over eight centuries, and is used for all basic operations: additions, subtractions, multiplications, and divisions. It is, for example, still quite common to see shopkeepers first use a calculating machine and then check the results with an abacus. If operated by expert hands the abacus is a most powerful tool and is even considered an art exemplifying order, cleverness, mental concentration, and the rational mind. In 1946, a contest paired a Japanese accountant and his abacus (Jp. soroban そろばん) and an operator using an electronic calculator (Matsuzaki versus Wood)..$^{10}$

The prayer that the viewer expected is replaced by an aggressive blare of contemporary sounds. Here Chen has turned a huge Tibetan prayer wheel into a kind of Wheel of Fortune, adopting a Buddhist saying accord-

10 On November 12, 1946, a speed contest was organized in Tokyo between the abacus manipulated by Kiyoshi Matsuzaki and an electronic calculator used by US Army soldier Thomas Nathan Wood, selected for his mastery of the tool. The tests were based on the four basic operations, as well as a problem that combined them all. The soroban prevailed by four to one, losing only on multiplication. 


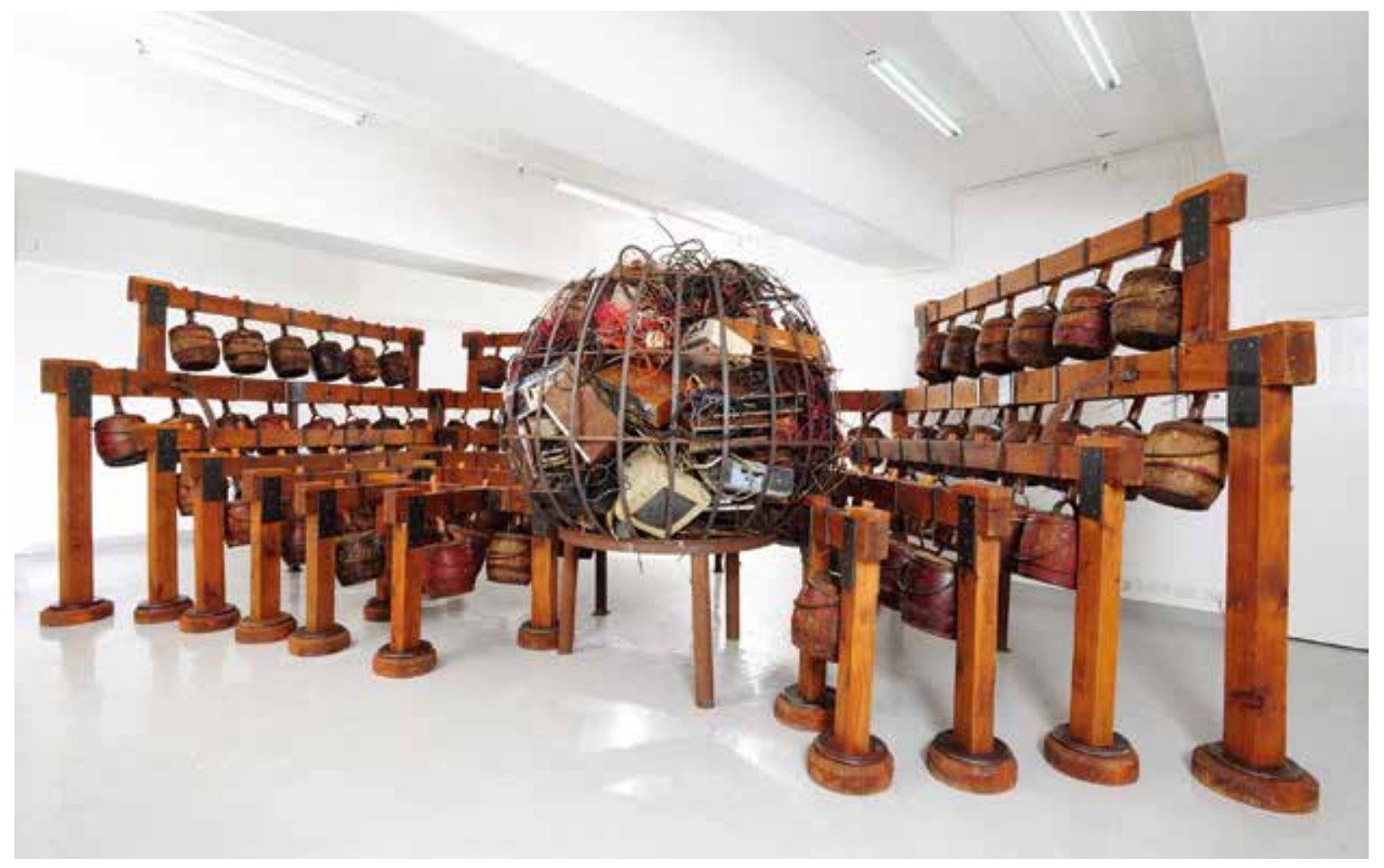

ing to which "Money makes the mare move forward."11 By doing this he looks ironically at human greed, which has made the chase for money a new world religion. Within a disturbing installation, the wheel takes on a fresh metaphorical meaning. Although it seemed about to give observers a taste of Buddhist meditation, each observer spins it as if in the hope of striking it rich. This is a violent intrusion of the values of a society that has, by Chen's implication, made money its only god. The artist enacts the tensions at work between the sacred and the profane, the material and the spiritual, the individual and the community.

11 In fact, it is a traditional English nursery rhyme (conserved in a 1609 manuscript in the British Museum):

Wilt thou lend me thy mare to ride but a mile?

No, she's lame goinge over a stile.

but if thou wilt her to me spare,

thou shalt have mony for thy mare.

ho ho say you soe

mony shall make my mare to goe.

The phrase means that if you are prepared to pay enough, most people will be willing to do something that at first they said

they would not or could not do. Chen Zhen uses this source in a humorous way by describing it as Chinese slang.
Figure 3. Chen Zhen. Daily Incantations. 1996. H. $230 \mathrm{~cm}, \mathrm{I} .700 \mathrm{~cm}$, w. $350 \mathrm{~cm}$. Wood, metal, Chinese chamber pots, electric wires, residues of electrical and electronic objects, sound system. Photograph used with permission of art wiki, http://www.artwiki.fr/wakka. php?wiki=ChenZhen.

By mixing the sounds of cash registers and Chinese abacuses into a sort of contemporary piece of music or prayer, Chen wanted to move beyond those noises by creating a religious atmosphere bathed in the subdued light reminiscent of a temple so as to draw observers into the meaning of its artistic installation. For him, "Sound allows for creating an extension of looking, a sort of trap for the spectators. Sound becomes the release mechanism for questions and interrogation in relation to the work itself." 12 In the earlier installation, Daily Incantations (1996, figure 3), he created a bianzhong 编钟, a set of royal Chinese bells associated with sacred places, but he replaced the bells with chamber pots. He added sounds of the pots being washed to snatches of political mumbo jumbo suggestive of read-

12 Sans, Chen Zhen, 265 
ings of Chairman Mao's Little Red Book. In fact, the recordings were political speeches from TV and radio programs in three different languages (English, French, and Chinese). Thus, those daily incantations were given a new contemporary dimension by creating a dialogue between contradictory energies.

Chen gives new meaning to ordinary everyday objects and re-interprets them. Although this is akin to a contemporary approach tending to dignify objects of the mundane world, he transforms such objects by drawing on their specific properties. This dematerialization process is sustained by the hitherto unsuspected physical and phenomenal properties of those "unworthy" objects that the artist brings to light using a complex strategy. The misappropriation and transformation of mundane items into bells or prayer wheels offer a semantic reversal. The artist questions the relationship between the Buddhist tradition, nature, and the proliferation of relatively short-lived objects. Bringing together objects not intended to be found in the same context is at the heart of Chen's methods. For him, "It's about contrast, contradiction and confrontation." ${ }^{13} \mathrm{He}$ does not consider art as having a mission. Art is rather about creating a space, bringing about the "the opportunity to create a misunderstanding," ${ }^{14}$ so that observers will seriously question what they thought they were sure of. He said to Eleanor Hearthney:

I'm not playing with the misunderstanding. I am trying to create it. This is my way of thinking. I want to make things more complicated. ${ }^{15}$

In Daily Incantations the controversial reception brings out a key element of Zhen's creative process, namely the misunderstanding that he considered a means of communication allowing singular mental reactions akin to his own experience. The materials used for his installations may indeed lead to misunderstandings. In 1996, when Chen and his friends collected 101 chamber pots manufactured in Shanghai for the Daily Incantations installation at the Jeffrey Deitch Gallery in New York, so as to create a set of bells reminiscent of a bianzhong, their action amounted to transgression. The artwork decontextualizes through chamber pots a famous Chi- nese archaeological discovery: the set of bronze bells from the tomb of the Marquis Yi of Zeng, dated to around 433 and discovered in 1977. Hung in a wooden frame and played melodically by striking them with a mallet, the bells produce magnificent music that is almost unique in the world's cultural history. The bells have an usual two-tone quality; each bell gives two different tones depending on where it is struck. The smallest one weighed $2.4 \mathrm{~kg}$ while the biggest weighed 203.6 $\mathrm{kg}$. Altogether, the instrument weighed over four tons. No other set of musical instruments on such a scale that can sound a complete twelve-tone scale has ever been found in China. Here the artist brings together two realities that bear no relation to each other: the mundaneness of street life where women wash the dirt off pots and the elegance of a palace or a temple. The pleasant sounds of the bells that would normally be heard are erased in favor of the percussive sounds.

Chen wished to avoid any systematic interpretations. The tension between visual components belonging to unconnected worlds is fruitful. The 101 traditional chamber pots that a western mind will instinctively appreciate for their aesthetic beauty-before becoming aware of their hygienic function - are hung in wooden frames. They encircle a very large globe filled with old radios, TV sets, telephones, and other debris of electronic communication. While we are initially attracted to the imposing and majestic shape of the "chime," we are startled when we discover the heap of waste. Chen brings face to face the ancestral vibrant memory of the traditional pots and that of ubiquitous present-day computers, displayed here as electronic waste. These juxtaposed life cycles are dissimilar: pots are looked after, cleaned, and potentially transformed into musical instruments, whereas electronic waste is piling up and suffocating the planet. The artist thus questions the objects and their role as a medium and "invader" in the globalization process.

Chen enjoys generating misunderstandings and has had to face numerous controversies about his artwork that the mundane character of his installation Daily Incantations underlines: the commonplace objects he uses are indeed initially meant for the collection of human excrement. He has turned banal everyday objects associated with our intimate lives into bells to create a colossal musical instrument from which emanate surprising sounds.

In 2000, the year Chen died, the Chinese embassy in Paris opposed the fact that Daily Incantations was fea- 
tured in the exhibition La Voix du Dragon at the Cité de la musique. ${ }^{16}$ The fact that the artist created a traditional set of bells using chamber pots to replace the bronze bells was simply unacceptable. Mrs Hou Xianghua, then Cultural Advisor at the Chinese embassy in Paris, declared: "I am shocked, Chinese people find this irreverent," before adding rather less diplomatically: "These chamber pots ... are just crap." ${ }^{\text {17 }}$

This scatological description stresses the triviality of the object, thus referring to the paradoxical nature of Chen's artwork, which plays on the double nature of an object. For most people in China, a chamber pot is an ordinary ugly, everyday object. The artist said: "In New York, Chinese visitors reacted by saying that it was horrible. To them the pots smelled foul and it was a shame to display them in an art gallery."18 Likewise many Western visitors, after perceiving the chamber pots as ancient beautiful Chinese objects, changed their minds when they became aware of their original intended function. However, to certain Chinese, the chamber pot is also emblematic of the renewal of generations. We can see that misunderstandings do indeed foster transcultural exchanges within which differences come alive.

For Chen, the use of found objects is not merely an aesthetic issue. The many layers of the objects' history as well as their political, economic, social, and cultural connotations are other aspects in which he is interested. The object is closely linked to the concepts of "Western world" and "modernization" and to the principle of "the old being replaced by the new." The nature of an object and the experience people have had with it are essential, as well as its transfer into different cultural contexts. Chen is filled with enthusiasm for "this extraordinary abundance behind each everyday ob-

\footnotetext{
16 "La voix du dragon. Trésors archéologiques et art campanaire de la Chine ancienne," exhibition held from November 21, 2000 to February 25, 2001, Cité de la musique (La Villette, Paris).

17 Le Journal des Arts 116 (December 1, 2000): 10-12. Chen was not welcomed by the Chinese embassy in Paris. Meant as a contemporary counterpoint to La Voix du Dragon, Chen's installation, Daily Incantations, was relocated to the other side of the Grande Halle de la Villette (Cité de la musique). "The Chinese embassy in Paris was shocked by Chen Zhen's creation of a traditional set of bells in which bronze bells had been replaced by wooden chamber pots," explained Emma Lavigne, curator of the Cité de la Villette, Musée de la musique. She added: "We had to relocate the installation or the exhibition would have been canceled." 18 Sans, Chen Zhen, 63.
}

ject"19 and confronts it with different contexts in order to provoke what he calls "the electrical short-circuit experience." ${ }^{20}$ As he put it:

Two opposite electrodes meet: they are not related but are from the same electrical circuit. What I am really interested in is the "shocking" and "destructive" power triggered by a "short circuit." That is creation. That is the most stimulating moment. ${ }^{21}$

The context that contributes to this phenomenon is directly linked to the physical location of the installation. The artwork is born from a confrontation and a dialogue within a particular context. In Chen's words,

I therefore feel that half of creation comes from the artist, his energy, his ideas, but that the other half comes from the context, from the other side, from the short-circuit. Two things that normally should not be connected, but when they are, they cause destruction and, at the same time, are releasing energy. ${ }^{22}$

The tensions at work in the creative process highlight this reality in all of Chen's installations, "the same approach of the contradictions present in the cultural, economic, spiritual and material world and toward all the conflicts brought about by the globalization of the capitalist system in various cultural environments." ${ }^{23}$

Capturing meaningful moments of everyday life urges Chen to ponder on the nature of objects and to encourage thinking by creating metaphoric tensions. All the objects that are altered and used in his installations belong to our everyday reality. The "quotidian," from the Latin word quotidie, meaning "every day," points to what is diurnal; "what happens every day and recurs every day," Georges Perec wrote, "the obvious, the common, the ordinary, the habitual." ${ }^{24}$ Like Chen, Perec has stressed the importance of banal things and urged us to question "that which seems to have ceased forever to astonish us, and that we usually fail to put into words." For him, the point is to try to understand

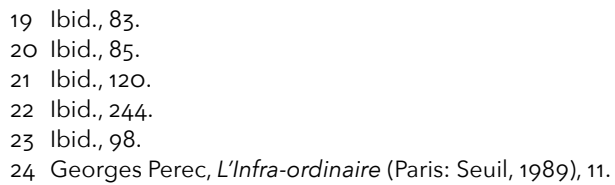


"what is underneath, the infraordinary, the background noise, our quotidian existence, each and every instant of it." 25

The concept of "post object" is recurrent in Chen's work. He gives new life to everyday objects that are not reprocessed and therefore keep their original aspect. Whereas an object is normally produced, consumed, thrown away, salvaged, displayed, preserved, or cast off, it is here offered a new destiny and reintroduced into new life cycles through an artistic process. In Prayer wheel- "Money Makes the Mare Go" (Chinese Slang), transforming abacuses and calculators into a huge prayer wheel introduces a new life cycle, even as that may seem paradoxical. For Chen, "These objects are there to purify a life after the use of the things, to sublimate a latent spirit after the death of the consumable circle of the products, to trigger a new destiny on the fatal conclusion of the objects." ${ }^{26}$ Recycling is not only about transforming a given material into another, or one item into something new. The sheer simplicity of the inanimate, unused object moves him, and urges him to give it a new life. He sees it as a shift from one life into another life. He goes on to say:

I think of this dimension of recycling as a turning back to the original point. It's a question of a rebirth, it's a question of birth, experience, death and rebirth. It's a circle of life. ${ }^{27}$

Chen's art opens up new horizons beyond the reality of things. He "loves all sorts of transformations, not only because they directly concern some aspects of reality, but also because they give us the opportunity to reveal, either indirectly or through metaphors, the essence of what is beyond objective reality." ${ }^{28} \mathrm{He}$ has succeeded in transforming ordinary material so as to question and shake up our relationship with images, with consumer society, and with objects.

There is no human representation in Chen's work, but his installations always include evocative objects such as tools, household or electronic appliances, clothes, furnishings (chamber pots, chairs, beds, and tables), newspapers, etc. The human body is clearly the

\footnotetext{
25 Georges Perec, "Entretien avec Jean-Marie Le Sidaner," L'Arc 76 (1979): 4.

26 Sans, Chen Zhen, 11

27 Ibid., 150.

28 Ibid., 151
}

pivotal element of Chen's work and is closely connected with his personal experience.

As mentioned before, Chen suffered from autoimmune hemolytic anemia for twenty years; this rare and incurable disease finally caused his death in 2000 at the age of forty-five. As early as 1992, he wanted to become a practitioner of traditional Chinese medicine because his condition both fostered and hampered his projects. The progression of his disease prompted him to make an issue and a philosophy of his life experience in order to turn it into an open, ever-active work. He strove to depict the conflicts between humans, nature, and consumer society within a wider perspective. Chen regarded the artist as a therapist, and declared that he was "concerned with the diagnosis of the world's diseases" and wanted "to reconcile man and the world." ${ }^{29}$ His approach aimed at spiritually bringing to life objects that both testify to and suffer from the society we live in.

Chen's works constantly question the world, following a cross-cultural way of thinking that links spirituality and technology, the material and immaterial dimensions. Central to his artistic work is the sharing of knowledge and skills in the fields of art, medicine, ecology, politics, and cultural identity between the two worlds to which he belonged. From a very early age, Chen, who grew up in a family of doctors, showed an interest in the relationships between traditional Chinese philosophy, which was forbidden in China in those days, and Western culture. In 1986, he chose exile in Paris. Chen was a genuine world citizen who could work equally well in New York, Shanghai, or Paris, his city of adoption.

Sharing one's culture and experience with others nurtured Chen's artistic projects. He spotlighted an "in-between" interval in which the relationships between contemporary art and life could find a fresh start. The concept of "in-between" is essential to his creative process. His strategy was driven by a wish to generate a dialogue and the sharing of experience between two cultures, two worlds, or two places, a pristine space that allows new opportunities to develop bonds, connections, and encounters.

Chen's artistic installations reveal the gap between the world and ourselves. Here is an artist who wished to work in the space between things, in this apparent void in which, when seen from another viewpoint, turns out

29 lbid., 8. 
to be an interval of plenitude and harmony. He questioned representation by creating a distance between image and object, between the object that is commonly used and the object as he recreated it. The artist remained faithful to the philosophical sources that enrich his work; he was aware that what occurs in images is what lies in the interval, in the space between things, in what lies "in-between" and eludes us. Taking a Taoist perspective, he considers that the genuine energy of our Universe does not reside in elements but rather in relationships. He says:

When I say relationships I really mean what is invisible, intangible, and immaterial: movements, shifts, exchanges and transformations that result in a dynamic process of change and evolution. ${ }^{30}$

Just as the Tibetan ritual wheel's prayers are scattered by movement, the work of art remains an inexhaustible entity within which any established form would come under threat of inertia if it were not constantly transformed by a creative energy that gives it life. The concept of incompleteness is a fundamental principle of any creative process. The work of art is a space open to change and new opportunities. Nothing is fixed. "Nothing is accomplished." ${ }^{31}$ Movement appears continuous and unfinished.

Chen's artistic strategy was driven, as was his life, by a constant wish to gather artists and the communities in which they live, in order to make them work together and better understand the differences and similarities between them. Chen believed in the ability of art to filter into all spheres of daily life and to find relevant connections with human concerns. Throughout his work, Chen built a genuine life project and thought pattern that he called "transexperience." This concept bears no relation to the experience of travelling, accessible to anyone who travels throughout the world, but which for him is "ultimately superficial and banal." 32

"Transexperience" consists of "spiritual loneliness and internalization of successive life experiences." ${ }^{33}$ The point is to adapt oneself, to multiply experiences and pay close attention to what is happening. This concept can be experienced by immersing oneself in life, mixing with other people, and identifying oneself with them. The purpose is to "become a kind of cultural homeless, belonging to nobody but possessing everything. This type of experience is a world in its own right." 34 To be constantly on the move is of the essence, as expressed in this Chinese proverb quoted by Chen: "Mobility offers people chances to survive, while trees will die if moved to another place." ${ }^{35}$ This is a mode of thinking and artistic creation that cross-fertilizes one's own experience and that of others. We must "dive into life, adapt to whatever circumstances we meet, mix and blend with others... Exactly how water does. Transparent, ever-changing, undulating and pervading everything; it gathers up all experiences, continents, men." 36

Chen emancipates mundane objects from their everyday constraints by displaying them in a place where time seems to stand still, so that a most ordinary reality expands, so to speak, to give rise to an infinite number of possibilities. Such installations as Daily Incantations or Prayer Wheel beckon to us so that we can converse with the world. Like the artist at work, observers do not see what they are looking at, but rather, "the way a thing looked at is co-present with them and the way they are co-present with this thing." ${ }^{37}$

Appearances are not misleading, and on the contrary invite the observer to look beyond. The word "appearance" reveals its complexity. It no longer refers here to an illusion, to something that conceals and mystifies, but rather harks back to its Latin origin, where apparare meant "presence." Presence refers to what exists here and now and can be perceived through our senses. ${ }^{38}$ It is a strength that deeply affects observers and invites them to share in a tangible experience.

In Chen's art everything invites us to have confidence in what is at hand here before us. The simplicity of an installation firmly anchored in material triviality requires going beyond appearances and better sharing the invisible elements. Catherine Francblin's remark

\footnotetext{
34 Sans, Chen Zhen, 67.

35 Ibid., 150.

36 Rosenberg and Min, Chen Zhen, 5

37 Maurice Merleau-Ponty, L'œil et l'esprit (Paris: Gallimard, 1964), 30.

38 The word Praesens as used by Emile Benveniste in Problèmes de linguistique générale I (Paris: Gallimard, 1974), 135
} 
about the often controversial works of Wim Delvoye is relevant when she notes that "the more a work appeals to the physical world, the stronger its metaphysical shock wave." ${ }^{39}$

\section{Bibliography}

Benveniste, Emile. Problèmes de linguistique générale. Paris: Gallimard, 1974.

Cage, John, translated by Vincent Barras. Silence: conférences et écrits. Genève: Éditions Héros-Limite, 2012.

Francblin, Catherine. "Wim Delvoye le diabolique." Artpress 277 (2002): 14-6.

Heartney, Eleanor. "Chen Zhen, 'entre' les cultures." Artpress 260 (2000): 25-7.

Merleau-Ponty, Maurice. L'oeil et l'esprit. Paris: Gallimard, 1964.

Perec, Georges. L'Infra-ordinaire. Paris: Seuil, collection La librairie du XXème siècle, 1989.

. "Entretien avec Jean-Marie Le Sidaner." L'Arc 76 (1979): 4-6.

Rosenberg, David, and Xu Min. Chen Zhen. Invocation of Washing Fire. Prato-Sienne: Editions Gli ori, 2003.

Sans, Jérôme. Chen Zhen: The Discussions. Dijon: Les presses du réel, Domaine Ecrits d'artistes, 2003.

39 Catherine Francblin, "Wim Delvoye le diabolique," Artpress 277 (2002): 16. 